Acta Poetica 29-1

PRIMAVERA

2008

\title{
El pan y la sal: \\ hacia una poética del gusto en el epigrama de Marcial
}

\author{
Amalia Lejavitzer Lapoujade
}

Por su importancia como alimento básico para las culturas mediterráneas, el pan y la sal tienen una gran relevancia dentro de la literatura occidental. Este artículo pretende rastrear la tradición que utiliza esos dos alimentos básicos como símbolos de una vida sencilla, y se centra en los epigramas de Marcial que mencionan el pan y la sal como metáforas del buen gusto.

As a consequence of its importance as basic nourishment, bread and salt have developed a great signifying relevance to Western literature. This article searches the examples that uses that products as symbols of a simple life, and is focused on Martial's epigrams that mentions bread and salt as metaphors of good taste.

Palabras clave: pan, sal, Marcial, gusto, sencillez 

Acta Poetica 29-1

PRIMAVERA

2008

Amalia Lejavitzer Lapoujade

\section{El pan y la sal:}

hacia una poética del gusto en el epigrama de Marcial

Toda la poesía es una inmensa traslación, es un ir de un lado para otro, de un lado, el que ven todos, al otro, al que sólo ven los poetas. Y escribir poesía es trasladar las palabras que tienen un uso diario y fijo a una tensión nueva donde valgan otra cosa y hasta signifiquen otra cosa.

PedRo SALinas

\section{Al pan, pan}

Dice Isidoro de Sevilla que el pan "se llamó pan, por el hecho de que se sirve (adponatur) con toda clase de comida, o por el hecho de que todo animal lo apetece (adpetat)"; de hecho, concluye, “en griego ‘todo' se dice pan”. ${ }^{1}$ Más allá de lo discutibles que pueden resultar las etimologías que el santo hispalense propone, llama la atención el cierre: 'todo' se dice pan.

En efecto, el pan es considerado no sólo la metonimia por antonomasia del sustento, ${ }^{2}$ sino también una metáfora de todo

1 Isid., Orig., 20, 2, 15: Panis dictus quod cum omni cibo adponatur, vel quod omne animal eum adpetat; $\pi \hat{\alpha} v$ enim Graece omne dicitur.

2 Pérez-Rioja 1971, 335. 
aquello que alimenta, tanto al cuerpo como al espíritu del ser humano. Para los pueblos mediterráneos, de ayer y de hoy, el pan constituye uno de los componentes básicos de su dieta, junto con el aceite de olivo y el vino, que forman la llamada tríada mediterránea de la alimentación. Al respecto, el mismo Isidoro de Sevilla afirmaba que "las comidas simples se dividen en dos [alimentos] necesarios: pan y vino". 3

En esas culturas mediterráneas, desde tiempos remotos, el pan fue asociado a lo que resulta esencial para la vida humana; en el Eclesiástico $(29,21)$, por ejemplo, se lee: "lo primero para vivir es agua, pan, vestido y una casa para abrigarse"; de aquí que, para los antiguos judíos, el pan sea símbolo de la providencia divina y del alimento primordial de su pueblo, pero también de todos los dones que Dios ofrece a los hombres, ${ }^{4}$ entre ellos, la sabiduría. ${ }^{5}$ Por su parte, en el Nuevo Testamento, Jesús dice (Jn 6, 35): "Yo soy el pan de vida, y el que viene a mí no tendrá hambre", ${ }^{6}$ con lo que el pan se vuelve el símbolo por antonomasia del alimento espiritual y, con ello, alcanza su más elevada significación simbólica: así, el pan trasciende el terreno de lo profano, para entrar indiscutiblemente en el ámbito de lo sagrado; el pan deviene amor, vida eterna, Dios mismo.

Los romanos también confirieron al pan una participación relevante en su vida cotidiana: piénsese en las distribuciones

${ }^{3}$ Isid., Orig., 20, 2, 5: Epulae autem simplices in duo necessaria dividuntur, panem et vinum.

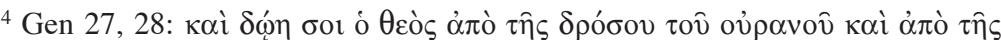

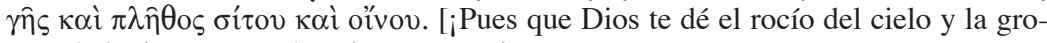
sura de la tierra, y mucho trigo y mosto!]

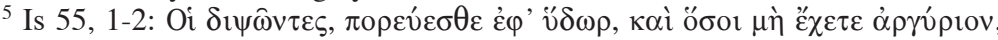

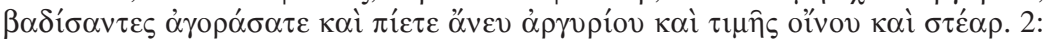

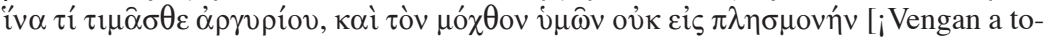
mar agua, todos los sedientos, / y el que no tenga dinero, venga también! / Coman gratuitamente su ración de trigo, / y sin pagar, tomen vino y leche. / ¿Por qué gastar dinero en algo que no alimenta / y sus ganancias, en algo que no sacia?]

${ }^{6} \mathrm{Cf}$. Mt 4, 4: non in pane solo vivet homo sed in omni verbo quod procedit de ore Dei [no sólo de pan vive el hombre, sino de toda palabra que sale de la boca de Dios]. 
gratuitas de trigo para elaborar pan (durante la república y los primeros tiempos del imperio) o de pan ya elaborado (en épocas más tardías), o en la manera en que los emperadores buscaban tener al pueblo bajo control. Según dice Suetonio, Calígula, por ejemplo, solía distribuir entre los espectadores a los juegos cestas llenas de panes (Calig., 18, 2, 14), y, en este mismo sentido, cabe recordar la muy célebre frase de Juvenal, panem et circenses ( $S ., 10,81)$, la cual, sin duda, remite a estas prácticas habituales. Otra evidencia de la importancia que para los antiguos romanos tuvo "el vivir de pan" es el hecho de que la profesión de pistor, ${ }^{7}$ panadero, fue muy apreciada, y por estos esclavos se pagaban altísimas sumas de dinero. Aulo Ge-

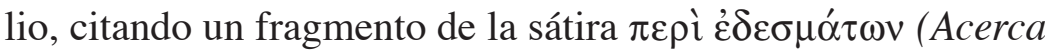
de los alimentos) de Varrón, dice con ironía:

si de cuanto trabajo te tomaste para que tu panadero hiciera el pan, hubieses dado a la filosofía la duodécima parte, ya hace tiempo te habrías vuelto bueno. Ahora, quienes lo conocen, quieren comprarlo en cien mil sestercios; nadie que te conozca, a ti en un ciento. ${ }^{8}$

El pan, precisamente por ser considerado un alimento humilde, ha sido asociado con la frugalidad y la moderación, tanto en los hábitos alimenticios, como en la conducta en general. Respecto a lo primero, cuenta Suetonio que Augusto comía muy poco, y cosas comunes, entre ellas, pan de segunda $;{ }^{9}$

\footnotetext{
${ }^{7}$ El pistor también hacía de pastelero, confitero o repostero, pues era el encargado de confeccionar panes dulces, tortas, pasteles y otras golosinas, como lo refiere Marcial en uno de sus epigramas $(14,222)$ : Pistor dulciarius. Mille tibi dulces operum manus ista figuras / extruet: huic uni parca laborat apis.

${ }^{8}$ Gell., 15, 19 (Varro, fr. 404 Bücheler): Si quantum operae sumpsisti, ut tuus pistor bonum faceret panem, eius duodecimam philosophiae dedisses, ipse bonus iampridem esses factus. Nunc illum qui norunt volunt emere milibus centum, te qui novit nemo centussis. La traducción es de Amparo Gaos Schmidt.

${ }^{9}$ Cf. Suet., Aug., 76, 1 y 2: Cibi [...] minimi erat atque vulgaris fere. Secundarium panem et pisciculos minutos et caseum bubulum manu pressum et ficos virides biferas maxime appetebat.
} 
respecto a lo segundo, tanto Aulo Gelio (VI, xvi, 7) como Ateneo (IV, $158 \mathrm{E}$ ) nos han conservado unos versos de Eurípides, donde el poeta trágico se pregunta:

¿Pues qué cosas son precisas a los mortales, excepto sólo dos: / el fruto de Deméter, [y] la bebida de agua fluyente, / las cuales están a la mano y nacieron para alimentarnos? / De ellas no nos basta la abundancia: por desenfreno, en verdad, andamos a caza de los artificios de otras viandas. ${ }^{10}$

En ese mismo sentido, Diógenes Laercio, en su Carta de Epicuro a Meneceo, afirma:

Las viandas simples proporcionan el mismo placer que la alimentación suntuosa, cuando todo sufrimiento debido a la necesidad se elimina, y el pan y el agua otorgan el más alto placer cuando los consume alguien necesitado. El habituarse, pues, a los alimentos sencillos y no suntuosos no sólo provee de salud, sino hace al hombre diligente [...], nos confiere mejor disposición [...], y nos vuelve carentes de temor a la suerte. ${ }^{11}$

Séneca, por su parte, refiere que el filósofo Posidonio atribuía la invención del pan a los sabios (Ep., 90, 22), y afirma que sólo es de admirar aquel hombre que logra despreciar has-

${ }^{10}$ Gell., VI, xvi, 7:

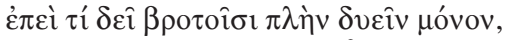

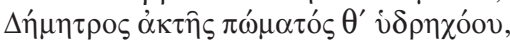

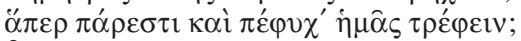

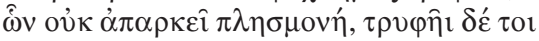

$\alpha ֶ \lambda \lambda \omega v \varepsilon \dot{\varepsilon} \delta \varepsilon \sigma \tau \hat{\omega} v \mu \eta \chi \alpha v \grave{\alpha} \theta_{\eta} \rho \omega ́ \mu \varepsilon \theta \alpha$.

La traducción es de Amparo Gaos Schmidt.

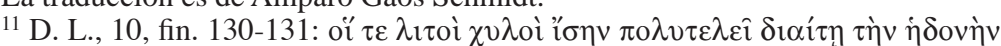

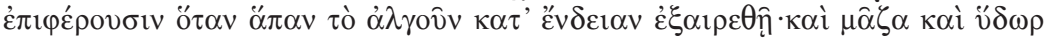

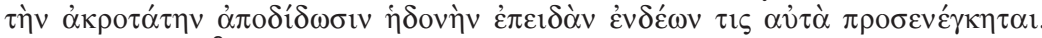

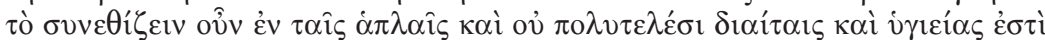

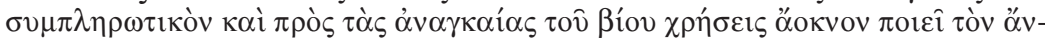

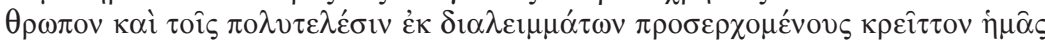

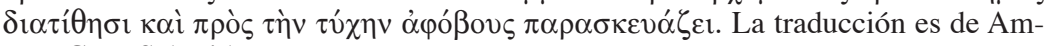
paro Gaos Schmidt. 
ta lo más necesario, como el pan común (Ep., 90, 12). Más aún, Séneca considera que el pan es el único alimento verdaderamente necesario (Ep., 25, 4), sin el cual no es posible la vida $(E p ., 45,10)$. También resulta muy ilustrativa la anécdota que, acerca de las circunstancias que rodearon la muerte de Demócrito, narra Diógenes Laercio, en sus Vidas de los filósofos más ilustres. Cuenta Diógenes que Demócrito, ya siendo muy anciano y a punto de morir, a fin de que su hermana pudiera rendir los debidos cultos en la cercana festividad de las Tesmoforias - casualmente, dedicadas a Ceres - , pidió que todos los días le llevaran pan recién horneado para olfatearlo $y$, gracias a su aroma, se mantuvo con vida durante los tres días que duraron las fiestas, pasados los cuales murió sin dolor alguno; el pasaje termina así: ${ }^{12}$

¿Y quién fue así de sabio?, ¿quién levantó obra tan grande como realizó el omnisciente Demócrito? Él, cuando se presentó la muerte, la tuvo tres días en su casa, y con tibias inhalaciones de pan la recibió como huésped. ${ }^{13}$

En efecto, el pan es emblema de austeridad y templanza, y representa de manera proverbial la sencillez. Probablemente, en la génesis de estos significados translaticios tenga que ver el hecho de que para hacer pan sólo se necesita harina y agua, pues levadura, huevos, miel, frutos, y otros componentes, siempre son opcionales. ${ }^{14} \mathrm{Al}$ respecto, dice Horacio que prefiere el pan a los pasteles de miel, ${ }^{15}$ en clara alusión a la vida humilde, campestre, conforme a natura, alejada del ruido,

${ }^{12}$ Cf. D. L., 9, 43, 12

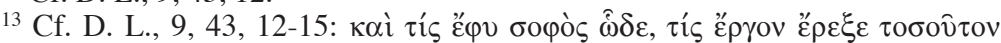

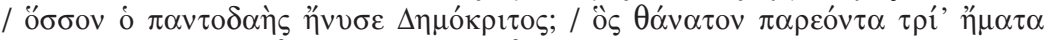

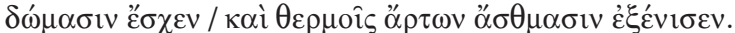

${ }^{14}$ Aunque el pan por antonomasia es el elaborado de harina de trigo, ya los griegos conocieron y elaboraron variedades de este alimento obtenidas a partir de salvado, centeno o avena, según refiere Ateneo en su Banquete de los sabios (III, 109 A-115 B), donde menciona más de 70 variedades de pan.

${ }^{15}$ Cf. Hor., Ep., 1, 10, 11. 
del trajín y de los excesos de la ciudad. Tal vez por ello, en el recetario atribuido a Apicio, que reúne muchos de los platillos que representan la cocina exótica y refinada de los romanos, el pan aparece mencionado en muy pocas recetas. ${ }^{16}$

Sin embargo, la aparente simplicidad del hacer pan implica un desarrollo cultural y un considerable avance tecnológico: para llegar al pan se debe pasar por un complejo proceso de transformación alimentaria, que comprende moler el grano que se va a utilizar (por medios manuales o mecánicos), mezclarlo con algún líquido (en general agua o leche), amasarlo, configurarlo, y, por último, cocerlo, primero sobre cenizas o sobre piedras ardientes, luego en hornos en los que, poco a poco, pudo regularse la temperatura de cocción. ${ }^{17}$

Por consiguiente, el pan también es símbolo de civilización y, más aún, constituye un rasgo distintivo de la naturaleza humana. Homero reconoció este valor "humanizador" del pan, cuando en la Odisea nombró a los hombres oı esto es, "comedores de pan", epíteto referido precisamente a la condición humana, en contraste con la del cíclope, "aquel prodigio monstruoso" que "no parecía un hombre que vive de pan", ${ }^{19}$ es decir, que no parecía humano.

En suma, el pan representa la imagen por excelencia de una vida humilde, frugal, honesta y moderada y, por ende, sabia. Al mismo tiempo, también simboliza todo aquello, material y espiritual, tangible e intangible, que resulta esencial para la humanidad. Por consiguiente, cuando Marcial declara que él prefiere a un lector que se sacie sólo con pan, en sus palabras debe advertirse una clara referencia a la vasta tradición literaria y cultural que lo precede. El poeta quiere un lector sencillo

\footnotetext{
${ }^{16}$ De las casi 500 recetas que constituyen el De re coquinaria, tan sólo en nueve de ellas se menciona el pan, y siempre aparece utilizado como un ingrediente más de la preparación. Cf. Apic., 48, 125, 126, 127, 276, 291, 292, 298 y 357.

${ }^{17}$ Cf. Sen., Ep., 90, 23.

${ }^{18}$ Cf. también Hdt., 4, 109.

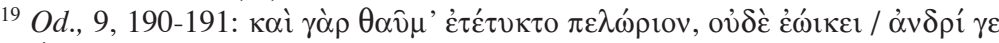

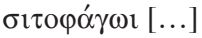


y humilde, a la par de sabio; quiere un lector que sepa reconocer lo que constituye alimento (stricto y lato sensu) esencial para el hombre; quiere un lector que sepa apreciar lo bueno, lo verdaderamente necesario, como el pan:

Consumpta est uno si lemmate pagina, transis, et breviora tibi, non meliora placent.

Dives et ex omni posita est instructa macello cena tibi, sed te mattea sola iuvat.

Non opus est nobis nimium lectore guloso. Hunc volo, non fiat qui sine pane satur. ${ }^{20}$

Si un solo epigrama consume una página entera, pasas de largo y te placen cosas más breves, no mejores.

Rica y servida con todo lo que hay en el mercado, se te ha preparado una cena, pero a ti sólo los manjares te agradan.

No necesito un lector demasiado goloso.

Quiero a aquel que, sin pan, no está satisfecho.

Aquí me parece significativa la posición enfática, en el segundo miembro del pentámetro, de las dos frases antitéticas mattea sola iuvat (del verso 4) y qui sine pane satur, cierre de la composición (del verso 6). La oposición entre ambas frases se hace más obvia por el verso intermedio: non opus est nobis nimium lectore guloso, que constituye la unión semántica de los dos conceptos contrarios. Esta oposición constituye una verdadera paradoja, que sirve al poeta para contraponer dos actitudes distintas, no sólo ante la comida, sino ante la poesía, y, sobre todo, ante la vida misma: la de aquel que, aunque tenga frente a sí una cena variada y espléndida, no se siente satisfecho, porque sólo le placen las gollerías (delicatessen, podríamos decir hoy), y la de aquel que, aunque disfrute de esa misma cena, variada y espléndida, incluso opulenta, sólo halla verdadera satisfacción cuando come pan. Sin duda, en estos

${ }^{20}$ Mart., 10, 59, 4-6. 
versos subyace no sólo una apreciación de crítica literaria, sino una valoración moral de la conducta: Marcial condena la gula, es decir, el apetito desenfrenado en el comer y el beber, pero también en el vivir.

Compartir el pan y la sal

En la vida diaria de épocas antiguas, compartir el pan y la sal fue una práctica habitual y muy arraigada. Por una parte, estos alimentos resultaban lo mínimo indispensable para la subsistencia; así lo indican las palabras con las que Odiseo increpa a Antínoo:

Tú no darías, de lo tuyo, ni sal a quien se te acercara, tú que ahora, sentado ante bienes ajenos, no te atreviste a tomar y a darme algo de pan: y de eso tienes en abundancia. ${ }^{21}$

Seguramente, la costumbre de acompañar una hogaza de pan con un puño de sal se deba no sólo a que, como refiere Plutarco, ${ }^{22}$ mezclado con sal, el pan mejoraba su sabor, sino a que esta práctica constituyó un recurso usual de los más pobres para mitigar el hambre: "con sal, el pan calmará bien a tu estómago ladrante", dice Horacio. ${ }^{23}$

Por otra parte, en el terreno de lo simbólico, compartir el pan y la sal implica compartir un lazo de fraternidad indestructible $;{ }^{24}$ quizá porque repartir a los demás lo poco que se tiene demuestra la generosidad y la caridad ${ }^{25}$ de que es capaz una

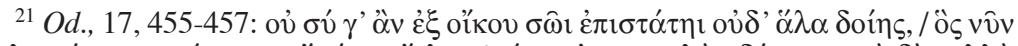

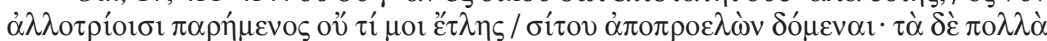
$\pi \alpha ́ \rho \varepsilon \sigma \tau \imath v$. La traducción es de Pedro C. Tapia Zúñiga (en la Odisea, investigación en proceso).

${ }^{22}$ Plu., Mor., IV, 668 E.

${ }^{23}$ Hor., Sat., 2, 2, 17-18: cum sale panis / latrantem stomachum bene leniet.

${ }^{24}$ Chevalier 1997, 859.

${ }^{25}$ Cabe aquí recordar los pasajes bíblicos de la "multiplicación de los panes", por ejemplo, Jn 6, 5-13, y Mt 14, 15-21.
} 
persona para con su prójimo, con lo cual, sin duda, se pone a prueba la verdadera amistad entre los hombres. De hecho, entre griegos y romanos existió un refrán popular que advertía que, para conocer a un amigo, era necesario haber consumido juntos muchos modios de sal. Así lo refiere Aristóteles, cuando dice que

no se debe tener un amigo sin ponerlo a prueba, no por un solo día, sino por mucho tiempo; por lo tanto, ha pasado a ser un proverbio lo del modio de sal. ${ }^{26}$

En otro pasaje de sus escritos éticos, el filósofo de Estagira insiste en la misma idea al hablar de la amistad perfecta, la que se da entre hombres semejantes en virtud; en su opinión, sólo esta amistad es en verdad perdurable, ya que

hace falta del tiempo y del trato, pues, según el proverbio, no es posible conocerse mutuamente los hombres antes de haber consumido juntamente la sal. ${ }^{27}$

Por su parte, Cicerón se hace eco de estas ideas al decir que la amistad

más antigua debe ser la más agradable, como esos vinos que resisten al tiempo; y es verdad aquello que se dice: que se deben comer juntamente muchos modios de sal para que sea colmada la tarea de la amistad. ${ }^{28}$

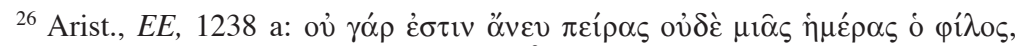

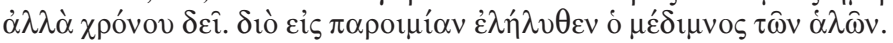

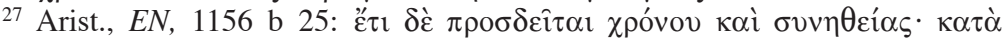

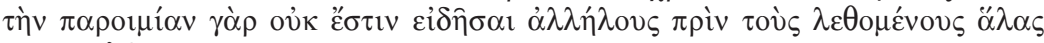
$\sigma v v \alpha v \alpha \lambda \omega \hat{\omega} \sigma \alpha 1$.

${ }^{28}$ Cic., De amicitia, 67: veterrima quaeque, ut ea vina, quae vetustatem ferunt, esse debet suavissima; verumque illud est, quod dicitur, multos modios salis simul edendos esse, ut amicitiae munus expletum sit. La traducción es de Julio Pimentel Álvarez. 
Aquí cabe hacer notar que Cicerón emplea el verbo edere, es decir, "comer", lo cual, refleja, por cierto, el hecho de que los romanos consideraban que la sal en sí misma constituía una verdadera comida, y además la tenían por un nutrimento muy saludable. En un principio, los soldados romanos recibían, como parte de su paga, un puñado de sal; ${ }^{29}$ posteriormente, esta ración fue sustituida por cierta cantidad de dinero que les permitiera comprar dicho producto, y afrontar así los gastos de la manutención cotidiana; sin embargo, aun cuando ya no consistía en el producto, sino en la suma para adquirirlo, dicha remuneración mantuvo el nombre de salarium. ${ }^{30}$

Al igual que el pan, la sal está ligada a lo esencial para la subsistencia humana, tanto en lo material como en lo espiritual. Desde los primeros tiempos de la humanidad, resulta un ingrediente fundamental no sólo para dar sabor a los platillos y para conservar los alimentos, sino para el sustento cotidiano. Isidoro de Sevilla, por ejemplo, dice que la sal resulta tan necesaria para la existencia humana como el sol o el agua:

Por su naturaleza, la sal es necesaria para todo alimento. Da sabor a los guisados, excita el hambre y despierta el apetito hacia toda clase de comidas. De ella, sin duda, viene todo el agrado y la máxima alegría por el alimento. De aquí, se piensa que la salud tomó su nombre. Nada hay, pues, más útil que la sal y el sol. ${ }^{31}$

Más aún, Plutarco explica con amplitud el hecho de que los antiguos consideraran que la sal, por sus nobles virtudes, era

\footnotetext{
${ }^{29}$ Para la distribución de sal a la armada, cf. Caes., B. C., 2, 37, 5: Castra erant ad bellum ducendum aptissima natura loci et munitione et maris propinquitate et aquae et salis copia, cuius magna vis iam ex proximis erat salinis eo congesta (Plut., Crassus, 19).

${ }^{30}$ Cf. M. Toussaint-Samat 1991, vol. 6, 40.

${ }^{31}$ Isid., Orig., 16, 2, 6: Salis natura necessaria est ad omnem escam. Pulmentis enim saporem dat, excitat aviditatem, et appetitum in omnibus cibis facit. Ex eo quippe omnis victus delectatio et summa hilaritas. Hinc et salus nomen accepisse putatur; nihil enim utilius sale et sole.
} 
el producto más grato a los dioses, y por ello, ya desde Homero, fue llamada divina sal. ${ }^{32}$

Ahora bien, en cuanto a su significación en el terreno de lo alegórico, la sal se relaciona con el ingenio, y siempre se alude a ella como a un paliativo contra el hastío, tanto de la comida como de la vida misma; además, por sus propiedades purificadoras, ha sido imagen de incorruptibilidad y pureza, dado que nada puede desalarla. Por ello, en el Antiguo Testamento, es símbolo de la alianza entre Dios y el pueblo hebreo, también nombrada "Alianza de sal", ${ }^{33}$ mientras que, en el Nuevo Testamento, Jesús exhorta a sus discípulos a ser "la sal de la tierra" (Mt 5, 13), a transmitir la verdad de Cristo, es decir, el alimento espiritual.

Para los griegos, "la sal es el símbolo de la amistad y de la hospitalidad, porque ella es compartida, y de la palabra dada, porque su sabor es indestructible"; ${ }^{34}$ pero también, al igual que el pan, representa una metáfora de la civilización, según se advierte en estos versos de la Odisea:

\section{márchate luego}

hasta que llegues a aquellos que el mar no conocen, esos hombres no comen comida mezclada con sal, ni conocen las naves $[\ldots] .^{35}$

Para los romanos, por su parte, la sal constituye una metonimia de la agudeza intelectual, del ingenio, de la astucia, de la sagacidad, incluso del sarcasmo, ${ }^{36} \mathrm{y}$, en el ámbito de la retórica, el término "salado" (salsum) designa al discurso que, con gracia e ingenio, movía generalmente a la alegría y a la risa. Quintiliano, por ejemplo, dice que "salado" se refiere a lo

\footnotetext{
${ }^{32}$ Cf. Plu., Mor. 384 E-385 F.

${ }^{33}$ Cf. Num, 18, 19; $2^{a}$ Cro, $13,5$.

${ }^{34}$ Chevalier 1997, 859.

${ }^{35}$ Od., 11, 121-124. La traducción es de Pedro C. Tapia Zúñiga.

${ }^{36}$ Cf. Lewis and Short, sub sal.
} 
que hace reír, porque toda expresión que hace reír debe estar acompañada por cierta sal, ${ }^{37}$ y entiende por "salado":

lo que no es insulso, así, por ejemplo, cierto sencillo condimento del discurso que se deja sentir por el juicio, como por el paladar, y que excita y defiende del tedio al discurso. Pues, a la manera que las sales, esparcidas con justa medida, añaden a la comida algo de su propia delicia, así también esos discursos que tienen sal añaden algo que nos hace tener sed de escuchar. $^{38}$

En suma, las palabras sal y salsum, la sal y lo salado, traspasan las fronteras de la cocina, y llegan a ser términos especializados de la retórica y de la crítica literaria, que designan una virtud del orador y una cualidad del discurso. El propio Quintiliano, por ejemplo, al referirse a las sátiras de Lucilio, dice que en ellas "hay admirable erudición y libertad, y también acritud y abundante sal". ${ }^{39}$ Asimismo, Plinio el Joven, en la carta donde anuncia la muerte de Marcial, escribe que "era un hombre ingenioso, agudo, ácido, quien al escribir tenía muchísimo de sal y de hiel"; ${ }^{40}$ aquí, tanto su certera apreciación literaria como su conciso juicio estético están impregnados de sabor.

En consecuencia, la sal metafóricamente resulta uno de los ingredientes indispensables para la elocuencia. ${ }^{41}$ Cicerón señala que el discurso no debe resultar insípido, ${ }^{42}$ toda oración

\footnotetext{
${ }^{37}$ Quint., 6, 3, 18: Salsum in consuetudine pro ridiculo tantum accipimus, natura non utique hoc est quantum et ridicula oporteat esse salsa.

${ }^{38}$ Quint., 6, 3, 19: Salsum igitur erit, quod non erit insulsum, velut quoddam simplex orationis condimentum, quod sentitur latente iudicio velut palato, excitatque et a taedio defendit orationem. Sales enim, ut ille in cibis paulo liberalius aspersus si tamen non sit immodicus, adfert aliquid propriae voluptatis, ita hi quoque in dicendo habent quiddam, quod nobis faciat audiendi sitim.

${ }^{39}$ Quint., 10, 1, 94: nam et eruditio in eo mira et libertas atque inde acerbitas et abunde salis.

${ }^{40}$ Plin., Ep., 3, 21, 1: erat homo ingeniosus acutus acer, et qui plurimum in scribendo et salis haberet et fellis.

${ }^{41}$ Cic., De O., 2, 23, 98: leporem quendam et salem.

${ }^{42}$ Cf. De O., 2, 59, 239: illud praecipitur, ne quid [sc. possis dicere] insulse.
} 
- dice - debe estar aderezada con $\mathrm{sal}^{43} \mathrm{y}$, en ese mismo sentido, el apóstol san Pablo aconsejará: "que vuestra conversación sea siempre amena, sazonada con sal". ${ }^{44}$

\section{Hacia una poética del gusto}

Ahora bien, cuando Marcial justifica la composición de uno de sus libros de epigramas, porque "el ebrio invierno pide nuevas sales", ${ }^{45}$ o cuando la Musa le ordena impregnar sus "encantadores libritos con sal romana", ${ }^{46}$ el poeta, sin duda, sustenta sus palabras en la nutrida herencia cultural y literaria de los siglos que lo anteceden. Es más, precisamente porque su obra está condimentada con sal, declara que su poesía no es insípida y que, por el contrario, tiene sabor (sapit): "mi página sabe a hombre". ${ }^{47}$

En efecto, el verbo latino sapio expresa, en sentido literal, "saber, gustar, tener sabor o gusto; tener sentido del gusto", en tanto que, en sentido translaticio, significa "tener buen gusto, tener sentido o discernimiento, ser sensible, discreto, prudente, listo, y asimismo saber, conocer, entender". ${ }^{48}$ Por lo tanto, cuando Marcial afirma que su página sabe (sapit), no sólo se refiere al "saber", como efecto del sabor, sino al "saber", como resultado del conocer. En efecto, su poesía tiene el sabor del hombre, pero también tiene conocimiento del hombre: su obra no sólo es sabrosa, sino también conocedora del ser humano y de su realidad. Más aún, en la obra de Marcial, que se basa

${ }^{43}$ Cf. De O., 1, 24, 159: quidam lepos quo tamquam sale perspergatur omnis oratio; también Cic., Or., 26, 87: huic generi orationis aspergentur etiam sales, qui in dicendo minimum quantum valent.

${ }^{44} \mathrm{Col}, 4$, 6: sermo vester semper in gratia sale sit conditus.

${ }^{45}$ Mart., 13, 1, 4: postulat ecce novos ebria bruma sales.

${ }^{46}$ Mart., 8, 3, 19: at tu Romano lepidos sale tinge libellos.

${ }^{47}$ Mart., 10, 4, 10: hominem pagina nostra sapit.

${ }^{48}$ Cf. Lewis and Short, sub sapio. 
en la experiencia y que apela a los sentidos, primordialmente al del gusto, el sabor y el saber adquieren un lugar privilegiado.

En el marco de sus libros de epigramas, el sentido del gusto se revela como un eje compositivo, polisémico, de donde surgen connotaciones diversas, pero no distantes entre sí, que abarcan el gusto por el buen comer, el buen gusto literario e incluso el gusto por vivir conforme a los ideales morales de los antiguos romanos, lejos de los excesos y depravaciones de los sibaritas de tiempos del poeta. Ejemplo de ello es el epigrama donde Marcial censura a un tal Zoilo, diciéndole que es más digno y puro cenar entre las prostitutas, y beber de sus copas inmundas, a ser un convidado suyo. ${ }^{49}$

Otras veces, Marcial alude al menú propio de una cena refinada para denunciar la corrupción del gusto:

Ni el salmonete te deleita, Bético, ni el tordo ni la liebre, ni jamás te es grato el jabalí [...]. Sospecho que tienes no sé qué secreto vicio del estómago: pues, ¿cómo, Bético, comes carroña $?^{50}$

De hecho, en sentido translaticio, se puede decir que la obra de Marcial constituye una cena que el poeta convida a sus lectores, ${ }^{51} \mathrm{y}$, a mi parecer, esta idea suya se encuentra condensada en el siguiente epigrama:

El lector y el oyente aprueban, Aulo, mis libritos, pero cierto poeta niega que estén logrados. No me preocupo demasiado:

${ }^{49}$ Mart., 3, 82, 1-4: Conuiua quisquis Zoili potest esse, / Summemmianas cenet inter uxores / curtaque Ledae sobrius bibat testa: / hoc esse leuius puriusque contendo.

${ }^{50}$ Mart., 3, 77: Nec mullus nec te delectat, Baetice, turdus, / nec lepus est umquam nec tibi gratus aper; / [...] / Nescio quod stomachi uitium secretius esse / suspicor: ut quid enim, Baetice, saprophagis?

${ }^{51}$ Pasoli, pp. 188-190. 
pues prefiero que los platillos de mi cena agraden a los convidados más que a los cocineros. ${ }^{52}$

La imagen de la cena reúne metafóricamente todo su universo literario, esto es, epigramas, libros, críticos y lectores. Esa cena que ofrece el poeta, aunque sencilla y sin ostentación, también resulta opulenta y variada, y, como el pan y la sal, gustosa y reconfortante para el estómago y el espíritu, apetentes de sabores y saberes nuevos: nos brinda comida y bebida de primera; es, pues, una poesía refinada. Así lo revela el siguiente epigrama:

Si mis libritos dicen algo agradable y dulce, si mi página, sugerente, emite algún son ennoblecedor, tú lo consideras basto, y prefieres roer una costilla, cuando yo te ofrezco un cuarto de jabalí de Laurento. Bebe vinos vaticanos, si te deleitas con vinagre: mi botella no está hecha para tu estómago. ${ }^{53}$

Aquí la alegoría de la cena permite a Marcial equiparar sus versos tanto a un manjar exquisito, que desprecia un lector ignorante de la valía de sus libritos, como a un vino de excelente calidad, que ese mismo lector no puede distinguir del vino vaticano, de pésima calidad.

Naturalmente, no a todos los lectores agradarán sus poemas, así como los variados platillos servidos en un banquete podrán deleitar o no a los comensales, según sus gustos; por ello, aconseja a su público: "pasa de largo, si algo no le sienta a tu estómago". 54

${ }^{52}$ Mart., 9, 81: Lector et auditor nostros probat, Aule, libellos, / sed quidam exactos esse poeta negat. I Non nimium curo: nam cenae fercula nostrae / malim conuiuis quam placuisse cocis.

${ }^{53}$ Mart., 10, 45: Si quid lene mei dicunt et dulce libelli, / si quid honorificum pagina blanda sonat, / hoc tu pingue putas et costam rodere mavis, / ilia Laurentis cum tibi demus apri. / Vaticana bibas, si delectaris aceto: / Non facit ad stomachum nostra lagona tuum.

${ }^{54}$ Mart., 13, 3, 8: praetereas, si quid non facit ad stomachum. Horacio, en Ep., $2,2,60$, utiliza la misma imagen. 
Marcial dirige sus poemas a los lectores de gustos sencillos y de costumbres honestas, capaces de discernir entre lo necesario y lo superfluo, que encuentran satisfacción en un trozo de pan, y que no se dejan seducir por el falso refinamiento que esconde tras de sí desenfrenos y excesos. Para el poeta, la cena ideal es aquella que refleja una vida sobria y una conducta moral proba; una cena en la que no tiene cabida ni fasto $(12,48)$ ni música $(9,77)$ ni molestas recitaciones $(3,50 ; 11,52)$ ni bailarinas lascivas $(5,78)$; una cena sencilla $(5,78 ; 10,48)$, sin lujos ni vicios $(3,82)$, compartida con los amigos $(10,48$; $11,52)$ y a la cual pueda corresponder:

Búscate otros comensales, a los que cautive la tiranía soberbia de tu mesa; que mi amigo me invite para unas improvisadas albóndigas. A mí me agrada esa cena, a la que puedo corresponder. ${ }^{55}$

En conclusión, podemos decir que la poesía de Marcial es sabrosa porque está condimentada con sal romana, pero también que, como el pan, se vuelve necesaria y, por extensión, sabia, porque, por una parte, su poesía refleja el profundo conocimiento que el epigramatista tuvo del ser humano; por la otra, sus versos también permiten que, en ellos, el ser humano de aquel tiempo - y de todos los tiempos - se conozca, y reconozca, a sí mismo. ${ }^{56}$ Más aún, así como se ha dicho que en los epigramas de Marcial palpita la vida, también podría decirse que ellos metafóricamente reúnen lo que en verdad resulta esencial para la vida: el pan y la sal.

\footnotetext{
${ }^{55}$ Mart., 12, 48, 15-18: Convivas alios cenarum quaere magister, / quos capiant mensae regna superba tuae: / Me meus ad subitas invitet amicus ofellas: / Haec mihi, quam possum reddere, cena placet.

${ }^{56}$ Cf. Mart., 10, 4.
} 


\section{Bibliografía}

BARBIERI, A., "Umorismo antico. Introduzione a Xenia e Apophoreta", Aevum, XXVII, 1953, pp. 385-399.

Brillat Savarin, J. A., Fisiología del paladar. Meditaciones de gastronomía transcendental, J. Oñaz de Ursua (ed. y trad.), s. 1., R \& B Ediciones, s. a., 369 pp.

Cicerón, Catón el Mayor: De la vejez. Lelio: De la amistad (tr., intr. y notas de Julio Pimentel Álvarez), México, UNAM, 1997 (Bibliotheca Scriptorum Graecorum et Romanorum Mexicana).

Chevalier, J., y A. Gheerbrant, Dictionnaire des Symboles, Paris, Robert Laffont/Jupiter, 1997, 1060 pp.

Citroni, Mario, "La teoria Lessinghiana dell'epigramma e le interpretazioni moderne di Marziale", Maia, 1969, pp. 215-243.

Gaos Schmidt, Amparo, "La carta de Epicuro a Meneceo", Noua tellus, 14, 1996, pp. 87-105.

Gellio, Aulo, Noches Áticas III, Libros XI-XVI (trad., notas e índice onomástico de Amparo Gaos Schmidt), México, UNAM, 2006 (Bibliotheca Scriptorum Graecorum et Romanorum Mexicana).

Lewis, C., y Ch. Short, A Latin Dictionary, Oxford, Clarendon Press, 1991 ( $1^{\mathrm{a}}$ ed. 1879), 2019 pp.

PASOl, Elio, "Cuochi, convitati, carta nella critica letteraria di Marziale", Museum Criticum, V-VI, 1970-1972, pp. 188-193.

Pérez-Rioja, J. A., Diccionario de símbolos y mitos, Madrid, Tecnos, 1971, $434 \mathrm{pp}$.

Real ACAdemia Española, Diccionario de la lengua española - Vigésima segunda edición, www.rae.es (versión electrónica).

Salanitro, María, "Carmina docta e cuochi in Marziale", Invigilata Lucernis, VII-VIII, 1985-1986, pp. 127-134.

_ "Il sale romano degli epigrammi di Marziale, (XIV.74)", Atene e Roma, XXXVI, 1991, pp. 1-25.

Salinas, Pedro, Mundo real y mundo poético y dos entrevistas olvidadas 1930-1933, Valencia, Pre-textos (Poéticas, 262), 1996, $101 \mathrm{pp}$.

Sullivan, J. P., Martial: The Unexpected Classic. A Literary and His- 
torical Study, Cambridge, Cambridge University Press, 1991, $\mathrm{XXV}+388 \mathrm{pp}$.

TOUSSAINT-SAMAT, Maguelonne, Historia natural y moral de los alimentos, Madrid, Alianza, 1991; vol. 6: La sal y las especias, $166 \mathrm{pp}$. 